УДК 632.931.1:631,582

06.01.00 Агрономия

МИНИМАЛИЗАЦИЯ ОБРАБОТКИ ПОЧВЫ И
ЕЕ ВЛИЯНИЕ НА АГРОФИЗИЧЕСКИЕ
ПОКАЗАТЕЛИ ЧЕРНОЗЕМА
ВЫЩЕЛОЧЕННОГО И УРОЖАЙНОСТЬ
ПОЛЕВЫХ КУЛЬТУР

Найденов Александр Семенович

д.с.-х.н., профессор

РИНЦ SPIN-код: 4925-1108

Бардак Николай Иванович

к.с.-Х.н., доцент ВАК

РИНЦ SPIN-код: 8194-8554

Терехова Светлана Серафимовна

к.с.-Х.н., доцент ВАК

РИНЦ SPIN-код: 3210-7883

Кравцова Наталия Николаевна

к.с.-Х.н., доцент ВАК

РИНЦ SPIN-код: 1944-1837

Кубанский государственный аграрный университет, Краснодар, Россия

В статье рассматриваются результаты исследований по влиянию обработки почвы на агрофизические показатели и урожайность основных полевых культур. В задачу исследований входило определение влияния основной обработки почвы(отвальная вспашка),поверхностная обработка(минимальная) и нулевая (прямой посев) - фактор А, минеральных удобрений - фактор В и гербицидов - фактор С на агрофизические свойства почвы. Установлено, что повышенная плотность приводила к значительному увеличению доли глыбистой фракции в структурном составе почвы. Ухудшение агрофизических свойств при минимизации обработки почвы отрицательно повлияло на водный, воздушный и пищевой режимы под культурами севооборота. При всех способах обработки почвы запасы влаги в слое 0200 см рано весной имели значения наименьшей влагоемкости (230-272 мм) и определялись особенностями погодных условий и предшествующей культурой. К моменту посева запасы влаги уменьшились на 12\%(203-241 мм). Наиболее экономно расходовали влагу растения на отвальной обработке почвы. В осенний период меньшее количество сорняков (7-11 шт./ $\left.\mathrm{M}^{2}\right)$ насчитывалось на вариантах по вспашке. При поверхностной и нулевой обработках почвы их число на $1 \mathrm{~m}^{2}$ было в $1.2-1.9$ раза больше. Эффективно уничтожение сорняков наблюдалось только при применении гербицидов. Различные культуры севооборотов по-разному реагировали
UDC 632.931.1:631,582

Agronomy

\section{MINIMIZING TILLAGE AND ITS EFFECT ON AGRO-PHYSICAL INDEXES OF LEACHED CHERNOZEM AND PRODUCTIVITY OF FIELD CROPS}

Naydenov Alexander Semenovich

Dr.Sci.Agr., professor

RSCI SPIN-code: 4925-1108

Bardak Nikolay Ivanovich

Cand.Agr.Sci., assistant professor

RSCI SPIN-code: 8194-8554

Terekhova Svetlana Serafimovna

Cand.Agr.Sci., assistant professor RSCI SPIN-code: 3210-7883

Kravtsova Nataliya Nikolaevna

Cand.Agr.Sci., assistant professor

RSCI SPIN-code: 1944-1837

Kuban State Agrarian University named after I.T.

Trubilin, Krasnodar, Russia

This article discusses the results of research on the effect of soil treatment on agro-physical performance and productivity of major field crops. The task of the research was to determine the impact of primary tillage (moldboard plowing), surface treatment (minimum) and zero (direct seeding) is factor A, fertilizers - B, and herbicides as factor $\mathrm{C}$ for agrophysical properties of soil. We have found that high density led to a significant increase in the proportion of the stone faction in the structural composition of the soil. Deterioration of the agro-physical properties while minimizing soil tillage has negatively affected water, air and food regimes under crops rotation. When all methods of soil tillage are applied, the moisture reserves in the $0-200 \mathrm{~cm}$ layer in early spring had the lowest values of moisture-holding capacity $(230-272 \mathrm{~mm})$ and were defined by the features of weather conditions and past cultures. At the time of sowing, their number decreased by $12 \%$ (203-241 $\mathrm{mm}$ ). The most economical way of spending moisture was shown by plants on the moldboard tillage. In autumn, fewer weeds $(7-11 \mathrm{PCs} / \mathrm{m} 2)$ there were in the options for ploughing. When the surface and zero ways of soil treatments were applied, their number for $1 \mathrm{~m} 2$ was 1.2-1.9 times bigger. We effectively eliminated weeds only when applying herbicides. Different crop cultures reacted differently to minimizing the tillage. The greatest reduction in yield was observed when applied surface and zero tillage in cultivated crops. Thus, studies have shown that in order to obtain maximum yields of field crops of crop rotation, reducing production costs, there must be a 
на минимизацию обработки почвы. Наибольшее снижение урожайности при применении поверхностной и нулевой обработки почвы наблюдалось у пропашных культур. Таким образом, исследования показали, что для получения максимальной урожайности полевых культур зернопропашного севооборота, снижения себестоимости продукции, необходимо рациональное сочетание глубокой или обычной отвальной обработки почвы под пропашные с поверхностной или нулевой под зерновые культуры

КлючевЫе слова: ОСНОВНАЯ ОБРАБОТКА, МИНИМАЛЬНАЯ (ПОВЕРХНОСТНАЯ), НУЛЕВАЯ (ПРЯМОЙ ПОСЕВ), ГЕРБИЦИД, АГРОФИЗИЧЕСКИЕ СВОЙСТВА, БОРЬБА С ЗАСОРЕННОСТЬЮ, УДОБРЕНИЯ, УРОЖАЙНОСТЬ

Doi: 10.21515/1990-4665-140-026 rational combination of deep or conventional plough tillage for surface or zero tilled for grain crops

\author{
Keywords: MAIN PROCESSING, MINIMUM \\ (SURFACE), ZERO (DIRECT SEEDING), \\ HERBICIDE, AGRO-PHYSICAL PROPERTIES, \\ FIGHT AGAINST CONTAMINATION, \\ FERTILIZERS, CROP YIELDS
}

\section{Введение}

В создавшихся экономических условиях увеличение производства зерна не может быть достигнуто за счет расширения площади посева. Важным условием выращивания конкурентоспособной продукции является использование новых, более толерантных и адаптированных к местным условиям сортов и гибридов, а также современные технологии их выращивания. При этом основное внимание должно уделяться энерго- и ресурсосбережению особенно при проведении наиболее затратного агроприема - обработка почвы. Переход от повсеместной вспашки к научно-обоснованному сочетанию еe c плоскорезной, чизельной и поверхностной обработками позволит существенно снизить затраты на выращиваемую продукцию.

В связи с эти изучение комплексного влияния на урожайность полевых культур, различных способов обработки почвы, норм минеральных удобрений на фоне применения химических средств защиты растений от сорняков, является актуальным, и имеет научное и практическое значение. Это позволит усовершенствовать технологии 
возделывания полевых культур и обеспечить получение высоких и устойчивых урожаев в Краснодарском крае

\section{Материалы и методика.}

Исследования проводились в 1996-2015 гг. в длительном стационарном опыте кафедры общего и орошаемого земледелия Кубанского аграрного университета на полях учебного хозяйства «Кубань»

Схема опыта трехфакторная. Фактор А - основная обработка почвы: отвальная вспашка, минимальная (поверхностная), нулевая (прямой посев). Фактор В - норма минеральных удобрений. Нормы минеральных удобрений составлены на основе рекомендаций по применению удобрений в Северо-Кавказском экономическом регионе (без удобрения, средняя норма удобрения, высокая норма удобрения). Фактор С - система защиты культуры от сорняков (ситуационная защита культуры (без применения гербицида), интенсивная защита, интегрированная защита.

Расположение делянок рендомизированное, повторность трехкратная. Учеты, наблюдения и анализы в опыте проводились согласно общепринятым методикам $(1,2,3)$. Агротехника в опыте рекомендуемая для Центральной зоны Краснодарского края. Учет урожая проводили отдельно с каждой делянки в фазу полной спелости зерна, с последующим пересчетом на стандартную влажность и 100\% чистоту.

Основная почвенная разность чернозем выщелоченный. Погодные условия в годы исследований были удовлетворительными.

\section{Результаты исследований и их обсуждение.}

Эффективность минимализации обработки почвы в основном зависит от гранулометрического состава почвы, степени и типа засоренности поля. Выщелоченные черноземы центральной зоны Краснодарского края имеют тяжелый гранулометрический состав, и по этой причине, минимализация их обработки не всегда приводит к http://ej.kubagro.ru/2018/06/pdf/25.pdf 
положительным результатам(4,5).

В длительном стационарном полевом опыте, заложенным кафедрой общего земледелия в 1996 г. изучались основные способы обработки почвы в сочетании с другими факторами под традиционные полевые культуры: озимую пшеницу, озимый ячмень, сою, кукурузу, подсолнечник и горох. Выявлено, что переход от традиционной отвальной обработки почвы к минимализации - поверхностной и особенно нулевой приводит к заметным изменениям агрофизических свойств почвы. Так, на вариантах с нулевой обработкой в слое 0 - 30 см объемная масса даже в начале весны (при достаточном содержании влаги в почве - 22 - $24 \%$ ) составляла 1,32 -

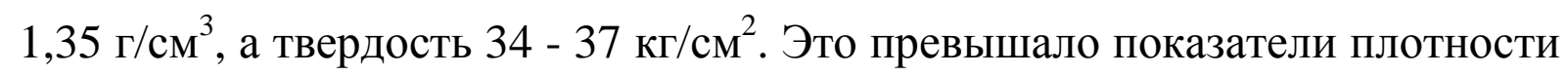

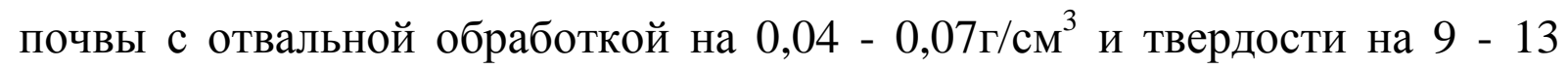

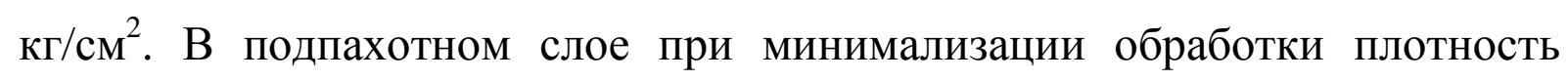

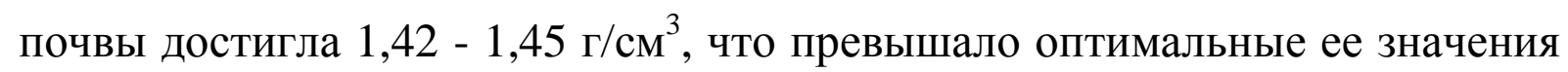
для многих сельскохозяйственных культур севооборота.

Мульчирующий слой из пожнивных остатков с.-х. культур при нулевой обработке почвы существовал короткое время. Затем происходила их быстрая минерализация. Так после уборки озимой пшеницы предшествующей сое и кукурузе воздушно-сухая масса соломы на 1 м² $^{2}$ составляла 5,12 - 5,67 кг. Весной перед посевом пропашных культур на фоне нулевой обработки почвы она уменьшалась до 0,92 - 1,42 г/см³, а в июне - июле здесь на поверхности поля оставались лишь следы $(0,4$ - 0,67 кг/ $\mathrm{M}^{2}$ ) пожнивных остатков. Процесс интенсивного разложения соломы колосовых культур обусловлен рядом причин: очень высокими температурами почвы в поверхностном слое (в дневные часы до 50 - 70 $\left.{ }^{\circ} \mathrm{C}\right)$, быстрым иссушением этого слоя при длительном отсутствии атмосферных осадков; возделыванием короткостебельных сортов пшеницы, формирующих небольшую вегетативную массу. Таким образом, можно предполагать, что применение нулевой обработки почвы в полевых http://ej.kubagro.ru/2018/06/pdf/25.pdf 
севооборотах Кубани, из-за указанных причин, не позволит создать постоянный мульчирующий слой на ее поверхности.

Как показали исследования, к основным недостаткам нулевой обработки почвы следует отнести:

- необходимость внесения более высоких доз минеральных удобрений (на 15 - 30\%);

-в первые годы внедрения резко повышается засоренность почвы, что вызывает необходимость обязательного применения гербицидов и более интенсивной защиты растений;

- на тяжелых почвах плотность может превышать оптимальные показатели для многих полевых культур;

-требуется высевать иммунные сорта сельскохозяйственных культур;

- при влажных условиях урожайность сельскохозяйственных культур ниже, в сравнении с отвальной вспашкой.

В годы с незначительным количеством осадков в летний период под пропашными культурами, посеянными по нулевой обработке почвы, наблюдалось интенсивное образование трещин (7 - 11\%). Их исчезновение происходило только при обильном выпадении осадков, в основном к окончанию вегетации сельскохозяйственных культур.

Повышенная плотность приводила к значительному увеличению доли глыбистой фракции в структурном составе почвы - до 47 - 55\%, что в 1,5 -1,7 раза больше чем при вспашке.

Ухудшение агрофизических свойств при минимализации обработки почвы отрицательно влияло на водный, воздушный и пищевой режимы под культурами севооборота. Так, под посевами сои, кукурузы и подсолнечника, в середине вегетации, общая пористость почвы в вариантах со вспашкой составляла 49 - 51\%, а при нулевой обработке она уменьшалась на 4 - 7\%. Содержание воздуха в общем объеме пор при http://ej.kubagro.ru/2018/06/pdf/25.pdf 
отвальной обработке составляло - 20 - 28\%, а при нулевой обработке - оно было на 6 - 8\% меньше.

При всех способах обработки почвы запасы влаги в слое 0 - 200 см рано весной имели значения наименьшей влагоемкости (230 - 272 мм) и определялись особенностями погодных условий и предшествующей культурой. К моменту посева пропашных культур их количество в указанном слое уменьшилось на 12 и варьировало по вариантам опыта от 203 до 241 мм. Отмечалась тенденция уменьшения потерь влаги в допосевной период в вариантах с нулевой обработкой почвы. Наиболее экономно использовали влагу растения в вариантах с отвальной системой обработки почвы, где коэффициенты водопотребления были в 1,3 -1,5 раза меньше в сравнении с нулевой обработкой. Это обусловлено главным образом, ухудшением условий роста и формирования урожая, в том числе и под влиянием значительной засоренности посевов.

Перед проведением предпосевной культивации под пропашные культуры засоренность на вариантах с отвальной системой обработки почвы была в 3,5 - 4,9 раза меньше, чем при поверхностной и нулевой. Применение гербицида Раундап до посева сои, кукурузы и подсолнечника не обеспечивало значительного уменьшения количества сорняков. Объясняется это тем, что поверхностный слой почвы имел большую потенциальную засоренность, а Раундап уничтожал только те сорняки, которые были на поверхности и не были покрыты стерней пшеницы или почвой. Более эффективное подавление сорняков наблюдалось при отвальной и поверхностной системах основной обработки почвы, где до посева пропашных культур вносили гербицид Харнес. Здесь количество сорняков в сравнении с первым сроком учета уменьшалось в 1,4 - 2,0 раза. В осенний период меньшее количество сорняков (7,5 - 10,9 шт./м²) насчитывалось на вариантах по вспашке. При поверхностной и нулевой обработках почвы, их число на $1 \mathrm{~m}^{2}$ было в 1,2- 1,9 раза больше. Особенно http://ej.kubagro.ru/2018/06/pdf/25.pdf 
значительное число сорняков (93 - 151 шт./м²) в вариантах с нулевой обработкой насчитывалось в посевах пшеницы весной. Они в основном были представлены зимующими видами: подмаренником цепким, маком самосейкой, яруткой полевой, ясколкой лесной и др., а также осотом розовым. Эффективное уничтожение этих сорняков, а также осота розового наблюдалось только при применении таких гербицидов, как Секатор или Лотус Д. Более полно о действии основной обработки почвы и гербицидов можно судить по зеленой массе сорняков с 1 м $^{2}$ в посевах озимой пшеницы. Самой значительной (117 - 149 г/м²) она была в вариантах с нулевой обработкой. По вспашке и поверхностной обработке почвы ее величина была в 3,2 -4,0 раза меньше. Разница в зеленой массе сорняков в зависимости от применения различных по спектру действия гербицидов была менее значительна и не превышала 7 - $11 \%$. Существенное снижение урожайности культур севооборота при применении нулевой обработке почвы в основном было связано с уменьшением густоты стояния растений пропашных и продуктивного стеблестоя колосовых культур [6]. Причем различные культуры севооборота по-разному реагировали на минимализацию обработки почвы (таблица 1). 
Таблица 1 - Урожайность сельскохозяйственных культур в зернопропашном севообороте в зависимости от системы обработки почвы ц/га (1996-2016 гг.)

\begin{tabular}{|c|c|c|c|c|c|}
\hline \multirow{3}{*}{$\begin{array}{c}\text { Культура, } \\
\text { предшественник }\end{array}$} & \multicolumn{5}{|c|}{ Система обработки почвы } \\
\hline & \multirow{2}{*}{$\begin{array}{c}\text { Отвальная } \\
\text { урожайность, } \\
\text { ц/га }\end{array}$} & \multicolumn{2}{|c|}{$\begin{array}{c}\text { Минимальная } \\
\text { (поверхностная) }\end{array}$} & \multicolumn{2}{|c|}{ Нулевая (прямой посев) } \\
\hline & & $\begin{array}{c}\text { урожайность, } \\
\text { ц/га }\end{array}$ & $\begin{array}{c}\text { в \% к } \\
\text { отвальной }\end{array}$ & $\begin{array}{c}\text { урожайность, } \\
\text { ц/га }\end{array}$ & $\begin{array}{l}\text { в \% к от- } \\
\text { вальной }\end{array}$ \\
\hline Соя & 21,1 & 17,6 & 83 & 13,4 & 63 \\
\hline $\begin{array}{l}\text { Озимая } \\
\text { пшеница }\end{array}$ & 77,1 & 72,5 & 94 & 61,2 & 79 \\
\hline Кукуруза-зерно & 55,6 & 36,4 & 65 & 33,6 & 60 \\
\hline $\begin{array}{l}\text { Озимая } \\
\text { пшеница }\end{array}$ & 55,9 & 54,4 & 97 & 47,9 & 85 \\
\hline Подсолнечник & 28,9 & 27,3 & 94 & 22,5 & 77 \\
\hline $\begin{array}{l}\text { Озимая } \\
\text { пшеница }\end{array}$ & 60,6 & 54,3 & 89 & 48,6 & 80 \\
\hline Озимый ячмень & 50,3 & 49,5 & 98 & 37,7 & 75 \\
\hline Гopox & 17,7 & 18,9 & 107 & 10,8 & 61 \\
\hline
\end{tabular}

Наибольшее снижение урожайности при применении поверхностной и нулевой обработке почвы наблюдалось у пропашных культур. Так, выращивание кукурузы и сои по нулевой обработке почвы снижало урожайность семян соответственно на 40 и $37 \%$ в сравнении с отвальной обработкой. Менее чувствительным к нулевой обработке почвы оказался подсолнечник. Урожайность семян на вариантах с нулевой обработкой почвы была только на 23\% меньше, чем по вспашке. Из изучаемых в опыте зерновых колосовых культур озимый ячмень более значительно снижал урожайность зерна при минимализации обработки почвы, чем озимая пшеница.

Уменьшение урожайности, по поверхностной и нулевой обработке почвы в сравнении со вспашкой составило соответственно 3-11 и $15-21 \%$. Очень 
существенно (в 1,5 раза) снижалась урожайность зерна гороха при нулевой обработке почвы.

Урожайность приведена с вариантов со средней дозой удобрений и применением гербицидов группы 2,4 Д. Разница в урожайности зерна озимой пшеницы на вариантах со вспашкой и нулевой обработкой почвы заметно уменьшалась при применении высоких доз удобрений (таблица 2). Таблица 2 - Урожайность озимой пшеницы в зависимости от способов обработки почвы и доз минеральных удобрений, ц/га

\begin{tabular}{|c|c|c|c|c|}
\hline \multirow[b]{2}{*}{ Обработка почвы } & \multirow[b]{2}{*}{$\begin{array}{c}\text { Доза } \\
\text { удобрений, } \\
\text { кг.д.в. }\end{array}$} & \multicolumn{3}{|c|}{ Предшественник } \\
\hline & & Соя & $\begin{array}{c}\text { Кукуруза на зер- } \\
\text { но }\end{array}$ & Подсолнечник \\
\hline \multirow{3}{*}{$\begin{array}{l}\text { Вспашка на 20-22 } \\
\text { см }\end{array}$} & Без удобрений & 63,7 & 47,9 & 51,6 \\
\hline & N120P60K40 & 77,1 & 62,4 & 65,8 \\
\hline & N240P120K80 & 78,1 & 64,8 & 69,8 \\
\hline \multirow{3}{*}{$\begin{array}{l}\text { Нулевая } \\
\text { обработка }\end{array}$} & Без удобрений & 41,6 & 33,8 & 30,4 \\
\hline & N120P60K40 & 61,2 & 53,9 & 43,4 \\
\hline & $\mathrm{N} 240 \mathrm{P} 120 \mathrm{~K} 80$ & 66,3 & 55,6 & 45,5 \\
\hline
\end{tabular}

Таким образом, исследования показали, что для получения максимальной урожайности полевых культур зернопропашного севооборота, снижения себестоимости продукции, необходимо рациональное сочетание глубокой или обычной отвальной обработки почвы под пропашные с поверхностной или нулевой под зерновые культуры.

Затраты (без стоимости материалов) на обработку почвы и уход за растениями при традиционной технологии возделывания озимой пшеницы после непаровых предшественников в среднем составили 1196 руб. на 1 га. Экономия затрат при этом в вариантах с минимальной обработкой почвы и при прямом посеве была соответственно 358 и 643 руб. на 1 га. Снижение http://ej.kubagro.ru/2018/06/pdf/25.pdf 
затрат на ГСМ на указанных вариантах в сравнении с традиционной технологией составляло соответственно 43 и $64 \%$.

Многолетние наблюдения и исследования по вопросу минимализации обработки черноземов Краснодарского края позволили выявить как отрицательные, так и положительные стороны ее применения.

К достоинствам минимализации и внедрении нулевой обработки почвы на черноземах Кубани следует отнести: экономию ГСМ и трудовых ресурсов (20 -30\%); полевые работы выполняются в оптимальные сроки; повышается устойчивость почвы к дефляции, сохраняется ее плодородие; увеличивается урожайность озимой пшеницы в годы с засушливым осенне-зимним периодом (при обязательном применении удобрений).

Таким образом, многолетние исследования, проведенные в стационарном опыте с обработкой почвы в полевом севообороте, показали, что для получения максимальной урожайности сельскохозяйственных культур, снижение себестоимости продукции целесообразно рациональное сочетание традиционной отвальной, плоскорезной или чизельной обработке почвы, под пропашные культуры с поверхностной или нулевой обработкой под зерновые.

\section{Список используемой литературы}

1. Доспехов Б.А. Методика полевого опыта /Б.А. Доспехов. - М.: Альянс, $2014-351$ с.

2. Методика государственного сортоиспытания сельскохозяйственных культур.М.: Колос,1972.-Вып.3 - 143 с.

3. Методические рекомендации по определению экономической эффективности использования научных разработок в земледелии. - Краснодар, 1986. - 61с.

4. Терехова С.С. Влияние минимализации обработки почвы на условия произрастания кукурузы и урожай зерна на обыкновенном черноземе Краснодарского края/С.С.Терехова, Т.А. Рутор, С.Е. Егоян//Знания молодых - новому веку: материалы молодых новому веку: материалы 2-й Международной научной конференции студентов Киров, 2007.-с. 42-52.

5. Найденов А.С. Доли влияния и эффект взаимодействия предшественников, минеральных удобрений и биопрепаратов на формирование листовой поверхности и урожайность озимой пшеницы на черноземе обыкновенном Западного Предкавказья/А.С.Найденов,С.С.Терехова,Ф.И.Дерека//Тр.КубГАУ,-2008.-№6 (16). 
6. Найденов А.С. Разработка элементов технологий возделывания озимой пшеницы на черноземе обыкновенном Западного Предкавказья. А.С.Найденов, С.С.Терехова, Т.А.Рутор, А.А.Коршунов//Плодородие.-2015-№1(82) с.10-14

\section{References}

1. Dospekhov B.A. Metodika polevogo opyta /B.A. Dospekhov. - M.: Al'yans,2014 $351 \mathrm{~s}$

2. Metodika gosudarstvennogo sortoispytaniya sel'skohozyajstvennyh kul'tur.- M.: Kolos, 1972.-Vyp. 3 - 143 s.

3. Metodicheskie rekomendacii po opredeleniyu ehkonomicheskoj ehffektivnosti ispol'zovaniya nauchnyh razrabotok v zemledelii. - Krasnodar,1986. $-61 \mathrm{~s}$.

4. Terekhova S.S. Vliyanie minimalizacii obrabotki pochvy na usloviya proizrastaniya kukuruzy i urozhaj zerna na obyknovennom chernozeme Krasnodarskogo kraya/S.S.Terekhova, T.A. Rutor, S.E. Egoyan//Znaniya molodyh - novomu veku: materialy molodyh novomu veku: materialy 2-j Mezhdunarodnoj nauchnoj konferencii studentov Kirov, 2007.-s. 42-52.

5. Najdenov A.S. Doli vliyaniya i ehffekt vzaimodejstviya predshestvennikov, mineral'nyh udobrenij i biopreparatov na formirovanie listovoj poverhnosti i urozhajnost' ozimoj pshenicy na chernozeme obyknovennom Zapadnogo Predkavkaz'ya/A.S.najdenov,S.S.Terekhova,F.I.Dereka//Tr.kubGAU,-2008.-№6 (16).

6. Najdenov A.S. Razrabotka ehlementov tekhnologij vozdelyvaniya ozimoj pshenicy na chernozeme obyknovennom Zapadnogo Predkavkaz'ya. A.S.Najdenov, S.S.Terekhova, T.A.Rutor, A.A.Korshunov//Plodorodie.-2015-№1(82) s.10-14 